\title{
TRANSITION TO ONLINE EDUCATION: RESEARCH OF VIDEO TEACHING CHALLENGES DURING COVID 19 PANDEMIC
}

\author{
Regina Miseviciene \\ Kaunas University of Technology, Lithuania \\ Vidmantas Rimavicius \\ Kaunas University of Technology, Lithuania \\ Dalius Makackas \\ Kaunas University of Technology, Lithuania
}

\begin{abstract}
Since 2020 middle of March many universities transposed the study process to online environment. Kaunas University of Technology within two weeks completely transferred the study process to the online space also. The following tools Zoom, Big Blue Button, Adobe Connect, MS Teams, Loom, Web Meetings have been offered for working remotely.

To reveal the learners' experience and evaluate the above-mentioned video conferencing technologies in the education process, the authors of this article conducted a case study involving 354 second-year students of the Faculty of Informatics. The case study was accomplished in June 2020, after the end of quarantine in our country.

The aim of the work was to reveal the learners' experience and summarize the results using different types of video conferencing systems.

The case study showed that the rapid transition to online form of education has been quite successful and that lessons learned can be used in the future in circumstances like COVID 19.

Keywords: COVID 19, online education, video conferencing systems.
\end{abstract}

\section{Introduction}

The COVID-19 pandemic has rapidly moved the educational process from traditional audiences to online. Such organization of education was the major change for the most students and educators. Although there should seem to have been no technology problems in the 21st century, as universities have been organizing distance learning for many years and were prepared for a variety of challenges, such abrupt changes made the situation much more difficult. It was difficult for educational institutions to move the whole study process to the online environment in a short time and start studies remotely.

The authors of the articles share their experiences of how their educational institutions have had to overcome these challenges. The authors of the article 
(Lameski, P., Bidikov, V., Kjiroski, K., Jakimovski, B., Zdravevski, E., Chorbev, I., \& Trajkovik, V., 2020) conducted a study based on a survey of students and teachers to find out the attitude towards online learning in classrooms and to learn good practices and solve the problems that have arisen. An article (Jayalath, C., Wickramasinghe, U., Kottage, H., \& Somaratna, G., 2020)conducted a case study to identify the challenges of online education in a pandemic. The article (Basilaia, G., \& Kvavadze, D., 2020) examines the ability of a country and its population to continue the educational process in the form of distance learning, reviews various available platforms that can be used for online education and face-to-face communication, and provides examples of their use. The authors of the article (Edelhauser, E., \& Lupu-Dima, L., 2020) focused on distance learning hardware and software and attempted to review the impact of distance education on students. The article (Mulenga, E. M., \& Marbán, J. M., 2020) seeks to answer the question of the impact that online learning has had on mathematics education. In the article. (Jena, 2020) describe distance learning tools and techniques that can ensure continuity of learning during a pandemic.

Since mid-March 2020, quarantine has been introduced in Lithuania. Measures have been taken to stop the outbreak of the virus, and many universities in the country have also moved the study process to the online space. Teaching and learning have shifted to distance learning. A study conducted in Lithuania (LMTP, 2020), already a few months after the start of the pandemic, showed that almost a third of educators had no experience working remotely before the pandemic, and work on organizing the teaching process remotely increased to 40 percent. The above study revealed that the following tools best met expectations in the distance learning process during quarantine: Moodle, Zoom, MS Teams, Google Aps.

Kaunas University of Technology within two weeks completely transferred the educational process to the online space also. The following tools Zoom, Big Blue Button, Adobe Connect, MS Teams, Loom, Web Meetings have been proposed for working remotely (KTU, 2020). As the live broadcasts of lectures (with or without recording) streaming tools Zoom, Big Blue Button, MS Teams, Adobe Connect and Loom were offered. Zoom and Big Blue Button platforms are integrated into Moodle. For direct counselling of individual students or groups and assessment of student works Moodle chats and Web Meetings tools were offered additionally.

The aim of the research was to reveal the learners' experience and to evaluate the above-mentioned video conferencing technologies in the learning process. The authors of this article conducted a case study involving about 350 secondyear students of the Faculty of Informatics. The case study was accomplished in June 2020, after the end of quarantine in the country. 
The next section present Gartner firm research of online videoconferencing platforms which enable virtual meeting scenarios according. The third section presents case study Kaunas University of Technology students experiences working with video conferencing technologies Zoom, Big Blue Button, MS Teams, outlines advantages and shortcomings that platforms. The findings of the case study are presented at the end.

\section{Analysis of Online Videoconferencing Platforms}

In the future, remote meeting IT solutions will grow as organizations increasingly adopt flexible working styles and cloud computing based services that allow the flexibilities.

Until 2024 teleworking and the changing demographics of the workforce will affect business meetings, with 74 per cent of companies planning to switch to videoconferencing permanently because of their experience through the forced isolation caused by COVID-19. All video conferencing systems will be based on Android or Windows devices, not traditional video devices (Fasciani, M., Eagle, T., Preset A., Doherty, B., 2020).

Gartner, the world's leading information technology research and advisory firm, rated information technologies sellers into 2020 Magic Quadrant for Meeting Solutions (Fasciani, M., Eagle, T., Preset A., Doherty, B., 2020). The survey helped uncover the vendors that best meet their needs for digital workplace platforms.

Gartner firm divided all sellers into four parts: Leaders, Challengers, Visionaries and Niche Players. The firm evaluated the software developers or companies based on criteria: the formation of a clear vision and the ability to implement it. These skills determine in which square the company occupies its position.

Leaders make a big impact in the market by being able to respond to customer needs. Leaders offer solutions for meetings with a wide variety of functions to ensure a variety of meeting scenarios, offer a large database, flexible financial solutions, and good supply. Leaders work great and they are promising.

Challengers are described by good reputation and prompt decisions in the meeting market. When compared to Leaders and Visionaries, their decisions may lack the same pace of innovation and collaborative functions to meet the full potential of meetings. They may lack an appropriate licensing model to meet market requirements.

Visionaries can deliver innovative software products that solve customer problems, but they have not yet developed a large installed base or large enough finances, so they are at risk of financial difficulties, problems selling or supporting developed products. 


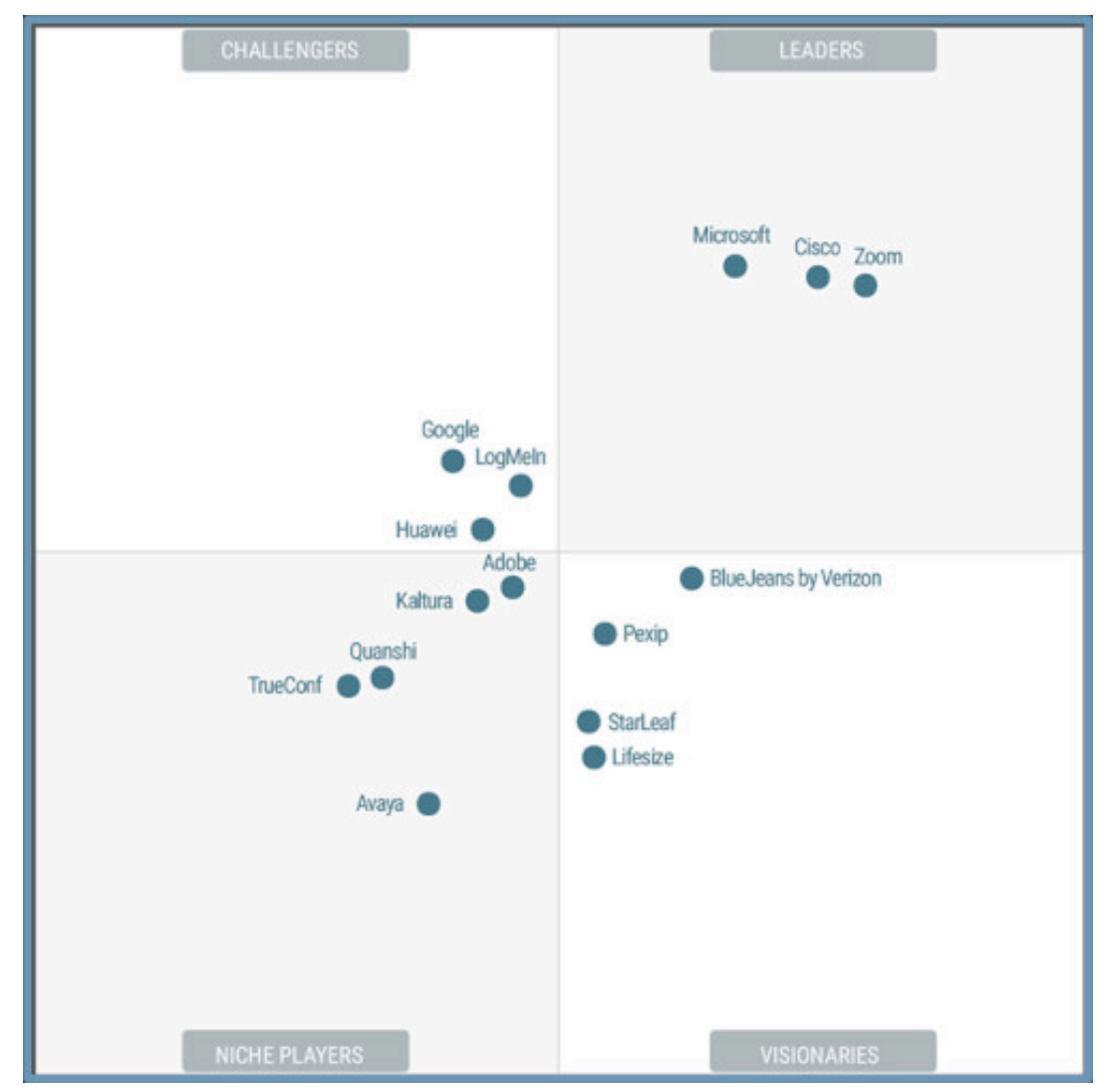

Figure 1 Magic Quadrant for Meeting Solutions.

(Source: (Fasciani, M., Eagle, T., Preset A., Doherty, B., 2020))

Niche Players can be targeted to a specific market or region by geography. However, they are limited by their size, the competitive pressure of more influential suppliers, their geographical coverage, and their financial situation. Companies may have implemented a wide range of software functionality, but with limited support capabilities and drastically low popularity among customers.

As it can be seen in Figure 1 the Gartner firm characterizes Zoom, MS Team and Cisco companies as Leaders of the 2020 Magic Quadrant.

Education institutions adopt flexible learning styles and cloud computing based services. The mentioned videoconferencing technologies allow teachers and students to collaborate with each other, sharing video and audio documents in real time as the teaching process takes place remotely. Participants can quickly access the learning sessions using mobile phones, video conferencing terminals for online meetings. Such conferences allow multiple participants not only to talk but also to transfer files like slides, static images, or text.

In the next section we analyze Kaunas University students experiences of the video conferencing technologies. 


\section{Case Study Findings}

To uncover learners 'experiences and evaluate the aforementioned video conferencing technologies to assess satisfaction criteria and potential problems we conducted a case study involving about 350 second-year students of the Faculty of Informatics. The case study was conducted in June 2020 after the end of quarantine in the country. The students needed to answer the questions: "How much and what video conferencing technology did you use to communicate with teachers this semester? List them and rate them on 10-point scale. What do you consider using the system advantages and disadvantages, and which you prefer in the future?

Most of the students and teachers for teaching and learning preferred using Zoom technology; the second platform was MS teams as the third system was Big Blue Button (Figure 2). Students also mentioned other platforms like Google Hangouts, Slack and Discord video conferencing.

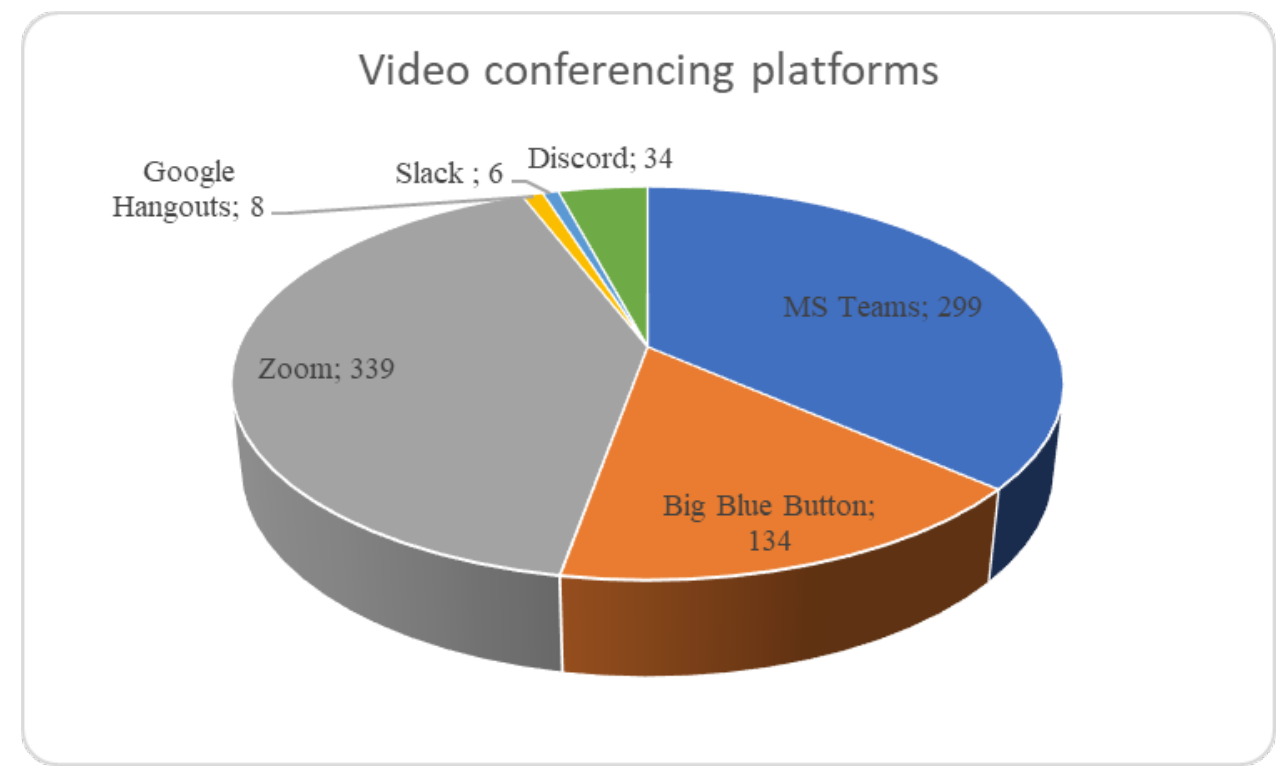

Figure 2 Video Conferencing Platforms Mentioned by Students in the Case Study

In the case study students rated Zoom video conferencing capabilities. Almost one third of the students rated the system between 7 and 9 on a ten-point scale (Figure 3). 


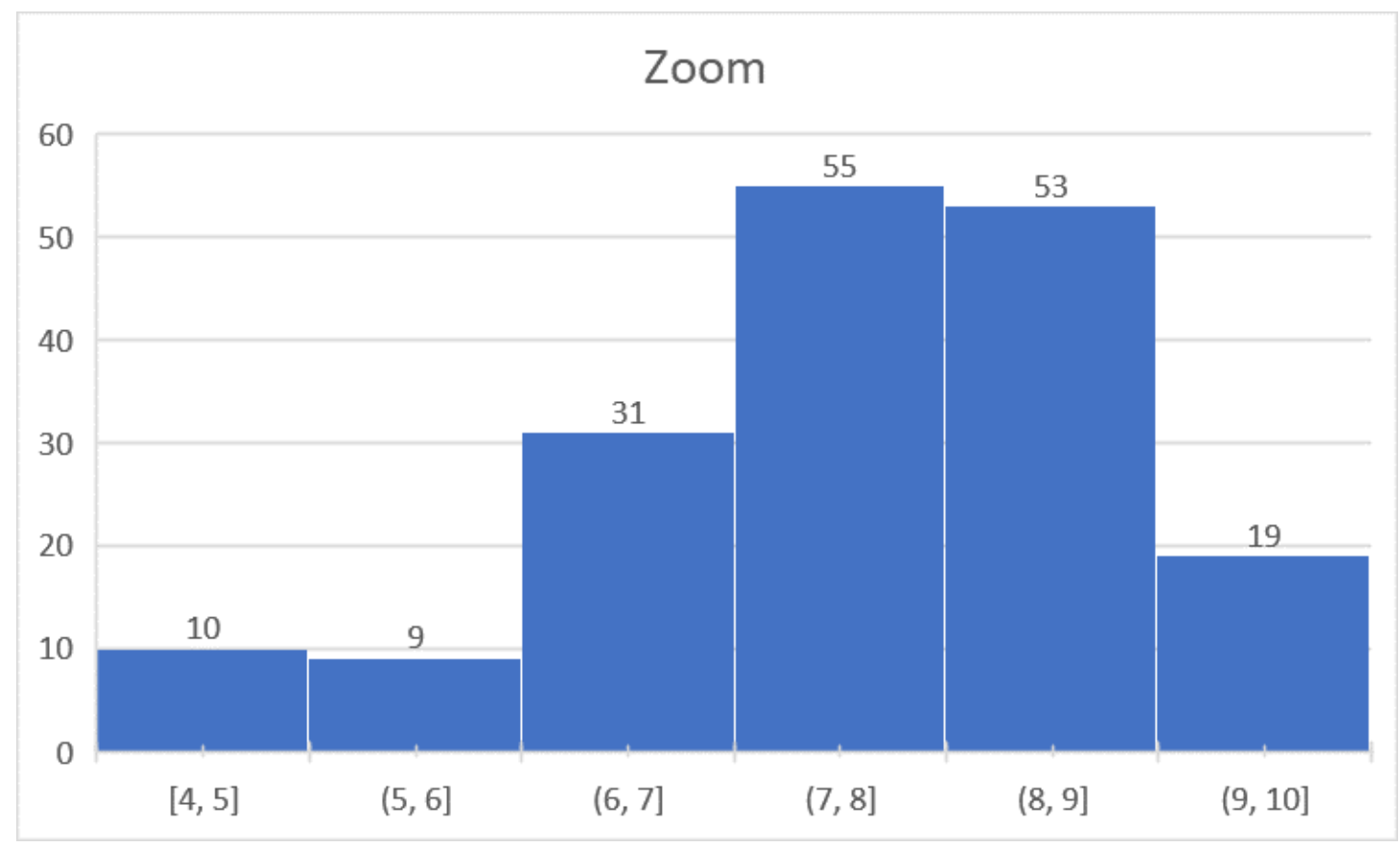

Figure 3 Zoom Platform Evaluation

Describing the work on this platform, the students mentioned that the platform is easy to use, can be connected directly from the browser, relatively good video and audio quality, simple user interface, convenient login, and applications management. One of advantages was mentioned that an application on the phone can be used when no way is to connect from computers, such as when moving further from home. Students also mentioned that the system is integrated with Moodle. The most convenient advantages are the screen share or moving the students to a separate break out rooms where the students can report the work individually or the teacher individually can show how to solve a specific task. Students mentioned that is also convenient to communicate and comment in the comments section. The "raise your hand" function is very useful.

The students also mentioned the shortcomings of the system. The problem was that work session had a time limit of 45 minutes if used without a license. Students mentioned that the system works great for theoretical lectures, but when it is necessary to share something with a student, the system has problems with the speed of the Internet and servers, very often the system crashes, sometimes cracked image, sound and there were problems with the microphone.

MS Teams platform was rated slightly more favorably. Figure 4 shows that this platform was rated between 9 and 10 points. 


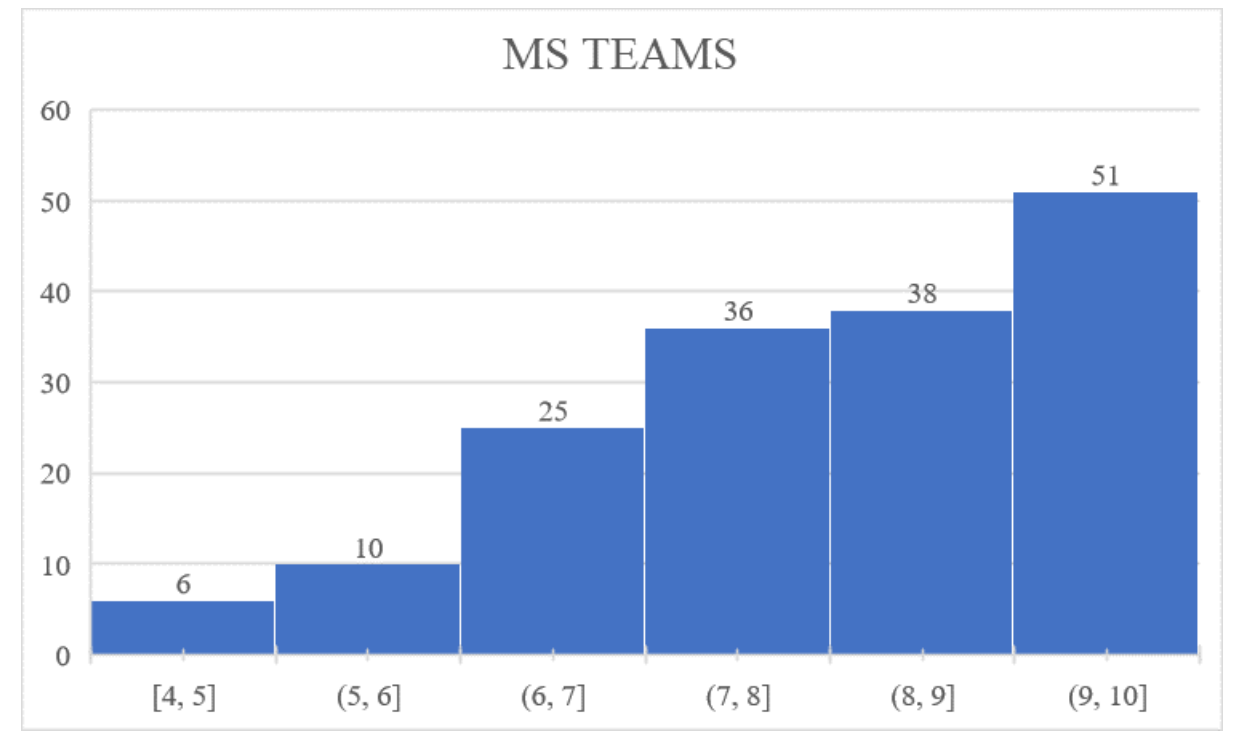

Figure 4 MS Teams Platform Evaluation

Because KTU licensed Microsoft services, the work is synchronized with the university e-mail, so all messages are sent to the e-mail before the lecture starts. The MS Teams system was easy to use, both on the phone and on the computer. This platform makes it easy to communicate both privately and in lectures (or groups). The system calendar shows when the lectures take place, there is no need to search for lectures through Moodle. The system is also convenient to use for communication with fellow students (for example, when working on one project), it is possible to add and store various documents, the whole history is clearly visible. Good enough personal messaging system, good video, and audio quality. Supports large numbers of people and is realistically designed to do large-scale conferences and lectures.

Not all students rated the system's capabilities so well. Some respondents mentioned that the interface of the platform is very confusing, the UI is difficult to understand, making it more difficult to understand how the platform works, it is not easy to catch which is exactly the intended activity. Students indicated that the system uses a lot of computer resources. Some respondents mentioned problems with screen transmission.

About a third of the respondents mentioned the third video conferencing platform Big Blue Button (Figure 5).

The platform received evaluations between 7-8 points. Students indicated that the system is quite convenient to use because no additional software is required, it is possible to log in via a browser. The platform is very suitable for theoretical lectures or those where the listeners do not need to speak, it is possible to vote by going directly to the lecture. In addition, teachers can comment as well in a general chat system. It is easy to understand how the platform works. Convenient for high flow, theory lectures. 


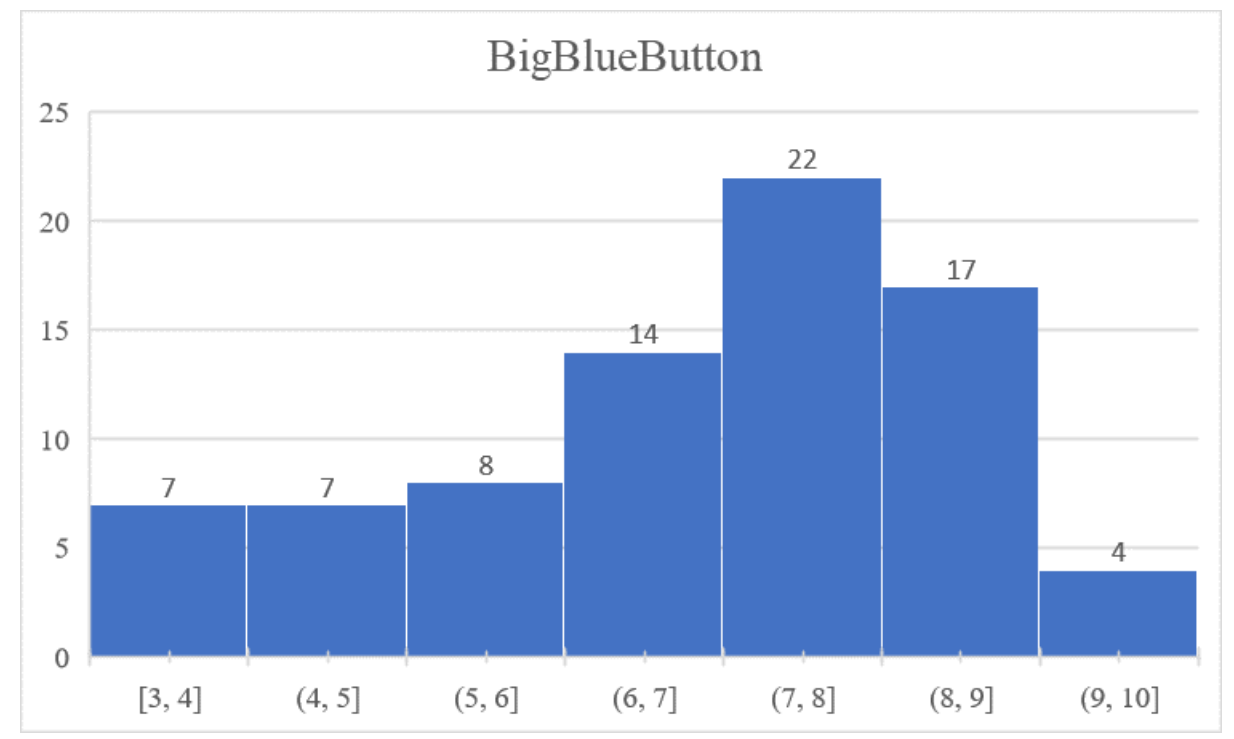

Figure 5 Big Blue Button Evaluation

Students also mentioned problems. Occasionally there were problems with sound or connection stability. Although the system is adapted for communication in larger audiences, with more than 100 students joining, there were problems with sound, communication interruptions occurred. Some respondents mentioned that it is difficult to communicate in private.

Among other video conferencing technologies, there was mentioned Discord platform, which was used by only a tenth of the students. In their responses, respondents mentioned that the platform has a very user-friendly design and structure, a role system, and administrative capabilities. Among the positive options, students mentioned that it is convenient to display a screenshot, easy to connect and disconnect from conversations, and the information that is written or sent to files does not disappear and can be seen at any time. The platform is free. The students mentioned that the Discord platform is more for game users but is great for adapting it to work and other purposes as well.

\section{Conclusions}

The case study showed that the rapid transition to online form of education has been quite successful. All mentioned video conferencing platforms provide ample opportunities for working remotely. The students also mentioned the shortcomings of the systems. Although students used the Zoom platform mostly, they rated best MS Teams technology.

The mentioned advantages and disadvantages of the systems allow University administration better to understand problems of learners. Lessons learned can be used in the future in circumstances like COVID 19. 


\section{References}

Basilaia, G., \& Kvavadze, D. (2020). Basilaia, G., \& Kvavadze, D. (2020). Transition to online education in schools during a SARS-CoV-2 coronavirus (COVID-19) pandemic in Georgia. Pedagogical Research, 5(4), 1-9.

Edelhauser, E., \& Lupu-Dima, L. (2020, 12 13). Is Romania Prepared for eLearning during the COVID-19 Pandemic?. . Sustainability, p. 5438.

Fasciani, M., Eagle, T., Preset A., Doherty, B. (2020, 10 12). Gartner Magic Quadrant for Meeting Solutions. Retrieved from Gartner: https://www.gartner.com/en/documents/ 3991618/magic-quadrant-for-meeting-solutions

Jayalath, C., Wickramasinghe, U., Kottage, H., \& Somaratna, G. (2020). Factors Influencing Orderly Transition to Online Deliveries during COVID19 Pandemic Impact. Asian Journal of Education and Social Studies, 10-24.

Jena, D. P. (2020). Challenges and Opportunities created by Covid-19 for ODL: A case study of IGNOU. International journal for innovative research in multidisciplinary field, 217-222.

KTU. (2020, 03 20). MOODLE practicality for teachers. Retrieved from Moodle: https://moodle.ktu.edu/mod/page/view.php?id=170894

Lameski, P., Bidikov, V., Kjiroski, K., Jakimovski, B., Zdravevski, E., Chorbev, I., \& Trajkovik, V. (2020). Transition from the classroom to online educational environment: First impressions. 17th International Conference on Informatics and Information Technologies - CIIT 2020.

LMTP. (2020, 06 20). Questionnaire for Teachers in higher education and Teachers in general education: working (teaching) remotely during the COVID-19 pandemic. Retrieved from apklausa.lt: https://apklausa.lt/f/aukstuju-mokyklu-destytojams-ir-bendrojo-ugdymomokyklu-mokytojams-skirta-ank-mrbxrtx/answers/new.html

Mulenga, E. M., \& Marbán, J. M. (2020). Mulenga, E. M., \& MIs COVID-19 the Gateway for Digital Learning in Mathematics Education? Contemporary Educational Technology, 12(2), 269. 